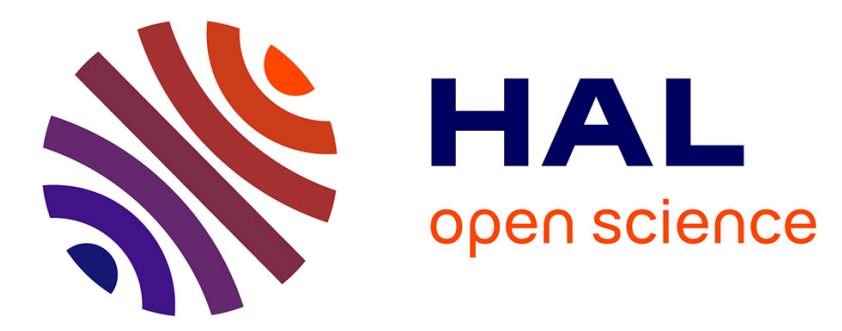

\title{
Sb-, Dy-, and Eu-doped oxyfluoride silicate glasses for light emitting diodes
}

Chaofeng Zhu, Xianghua Zhang, Hongli Ma, Claire Timlin

\section{To cite this version:}

Chaofeng Zhu, Xianghua Zhang, Hongli Ma, Claire Timlin. Sb-, Dy-, and Eu-doped oxyfluoride silicate glasses for light emitting diodes. Journal of Alloys and Compounds, 2015, 647, pp.880-885. 10.1016/j.jallcom.2015.05.186 . hal-01231148

HAL Id: hal-01231148

https://hal-univ-rennes1.archives-ouvertes.fr/hal-01231148

Submitted on 24 Nov 2015

HAL is a multi-disciplinary open access archive for the deposit and dissemination of scientific research documents, whether they are published or not. The documents may come from teaching and research institutions in France or abroad, or from public or private research centers.
L'archive ouverte pluridisciplinaire HAL, est destinée au dépôt et à la diffusion de documents scientifiques de niveau recherche, publiés ou non, émanant des établissements d'enseignement et de recherche français ou étrangers, des laboratoires publics ou privés. 


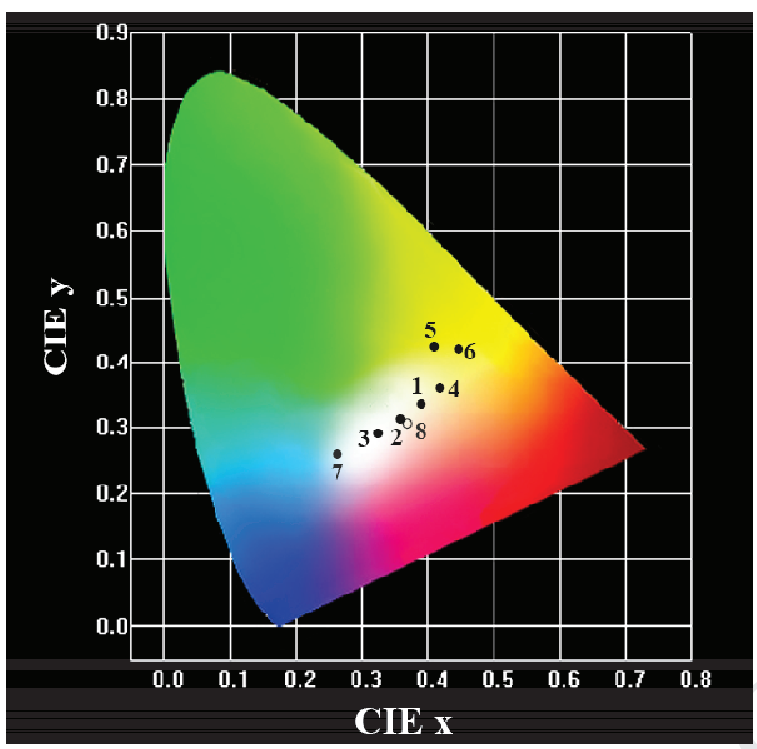




\title{
Sb-, Dy-, and Eu-doped oxyfluoride silicate glasses for light emitting diodes
}

\author{
Chaofeng Zhu ${ }^{\mathrm{a}, \mathrm{b},{ }^{*},}$ Xianghua Zhang ${ }^{\mathrm{b}}$, Hongli Ma ${ }^{\mathrm{b}}$, Claire Timlin $^{\mathrm{c}}$ \\ ${ }^{a}$ Key Laboratory of Processing and Testing Technology of Glass \& Functional Ceramics of Shandong \\ Province, Qilu University of Technology, Jinan 250353, P.R. China \\ ${ }^{b}$ Laboratoire des Verres et Céramiques, UMR-CNRS 6226, Université de Rennes 1, Rennes 35042, France \\ ${ }^{c}$ Department of Physics, University of Oxford, Oxford OX1 3RH, United Kingdom
}

\begin{abstract}
A series of Sb-, Dy-, and Eu-doped oxyfluoride silicate glasses for light emitting diodes (LEDs) applications were prepared via the melt-quenching method, and studied by a) photoluminescence emission and excitation spectra, b) decay curves, c) Commission Internationale de L'Eclairage (CIE) chromaticity coordinates, and d) correlated color temperatures (CCTs). We discover the energy transfer from $\mathrm{Sb}^{3+}$ to $\mathrm{Dy}^{3+}$ ions occurs in $\mathrm{Sb} / \mathrm{Dy}$ co-doped glass. We also find the emission behavior of $\mathrm{Sb}^{3+}$ single doped glass is dependent on the excitation wavelength. Furthermore, the white light emission can be achieved in $\mathrm{Sb} / \mathrm{Dy} / \mathrm{Eu}$ co-doped oxyfluoride silicate glasses under ultraviolet (UV) light excitation. The results presented here demonstrate that the as-prepared $\mathrm{Sb} / \mathrm{Dy} / \mathrm{Eu}$ doped oxyfluoride silicate glasses may serve as a potential candidate for LEDs-based lighting.
\end{abstract}

Keywords: Luminescence; Glasses; Energy transfer

\section{Introduction}

\footnotetext{
${ }^{*}$ Author to whom correspondence should be addressed. E-mail: chaofengzhu@gmail.com (C.F. Zhu).
} 
Nowadays, luminescent glasses play an increasingly significant role in many fields [1-5], such as laser technology, color display, general lighting, optical communication, silicon photovoltaic solar cells, fiber amplifiers and waveguides etc. Luminescent glasses for light emitting diodes (LEDs) based lighting applications have recently attracted substantially more research attention [6-9], because they demonstrate superior physical properties and optical performances compared to the conventional powder phosphors [6-9]. In other words, luminescence glass based LEDs are considered to be an interesting and highly advantageous alternative approach to traditional phosphor converted LEDs which are fabricated by combining InGaN-based LED chips with phosphor and organic resin.

$\mathrm{Sb}$ is a promising low-cost and environmentally-friendly element. $\mathrm{Sb}_{2} \mathrm{O}_{3}$ is used, for example, as a fining agent in glass melting. Although some investigations on the emission of $\mathrm{Sb}^{3+}$ have been reported $[\mathbf{1 0 , 1 1}], \mathrm{Sb}^{3+}$ has not been further considered as an emission center in conventional glass science. On the other hand, the oxyfluoride silicate glasses are important materials with excellent thermal and chemical stability, high mechanical strength, as well as low phonon energy environment for luminescence ions [7,12]. In the present work, we fabricated a series of Sb-, Dy- and Eu-doped oxyfluoride silicate glasses for LEDs by the melt quenching method in air atmosphere. Until now, only preliminary results on the luminescent glasses or glass-ceramics for LEDs have been reported [13-15]. R.F. Wang et al. investigated $\mathrm{Eu}^{3+} / \mathrm{Tb}^{3+}$ co-doped $\mathrm{SiO}_{2}-\mathrm{AlF}_{3}-\mathrm{BaF}_{2}-\mathrm{PbF}_{2}-\mathrm{GdF}_{3}$ luminescent glass and glass-ceramics for LED applications [14]. Compared with glasses, the coordination environment around $\mathrm{Eu}^{3+}$ in the glass-ceramics is changed from the Cs symmetry to inversion symmetry, thus the emission characteristic of $\mathrm{Eu}^{3+}$ is changed and results in color tunable luminescence. They also 
examined the energy transfer process between $\mathrm{Eu}^{3+}$ and $\mathrm{Tb}^{3+}$ ions. Structural and luminescence properties of $\mathrm{Dy}^{3+}$ doped $\mathrm{B}_{2} \mathrm{O}_{3}-\mathrm{P}_{2} \mathrm{O}_{5}-\mathrm{Al}_{2} \mathrm{O}_{3}-\mathrm{PbO}-\mathrm{ZnF}_{2}-\mathrm{Bi}_{2} \mathrm{O}_{3}$ glasses for white LEDs were studied by M. Vijayakumar et al. [15]. The nephelauxetic effect and Judd-Ofelt theory are applied to investigate the nature of the Dy-O bond and local environment around the $\mathrm{Dy}^{3+}$ ion site. They also studied the yellow/blue emission intensity ratios by varying the concentration of $\mathrm{Dy}^{3+}$ and excitation wavelengths. While, the Sb/Dy/Eu co-doped oxyfluoride silicate glasses have not been reported. The current study mainly concerns the influence of the excitation wavelengths as well as glass compositions on the luminescent properties of the glasses. In this work, we report the tunable light emissions of Sb-, Dy-, and Eu- doped oxyfluoride silicate glasses, and discuss in detail the energy transfer from $\mathrm{Sb}^{3+}$ to $\mathrm{Dy}^{3+}$ ions. The objective is to achieve efficient white light emission. The findings reported here are scientifically intriguing and could also provide knowledge for the fabrication of future optical devices.

\section{Experimental}

All the investigated glasses have the glass matrix (GM) composition of $45 \mathrm{SiO}_{2}-15 \mathrm{Al}_{2} \mathrm{O}_{3}-10 \mathrm{ZnO}-20 \mathrm{CaF}_{2}-10 \mathrm{CaO}$ (in mol.\%). Samples GMS4 (doped with 4 mol.\% Sb), GMD0.5 (doped with 0.5 mol.\% Dy), GMS4D0.5 (co-doped with 4 mol.\% Sb and 0.5 mol.\% Dy), GMS4D0.5E0.3 (co-doped with 4 mol.\% Sb, 0.5 mol.\% Dy, and 0.3 mol.\% Eu), and GMS4D0.5E0.5 (co-doped with 4 mol.\% Sb, 0.5 mol.\% Dy, and 0.5 mol.\% Eu) were prepared by melt-quenching method in normal atmosphere. $\mathrm{SiO}_{2}, \mathrm{Al}_{2} \mathrm{O}_{3}, \mathrm{ZnO}, \mathrm{CaF}_{2}, \mathrm{CaCO}_{3}$, $\mathrm{Sb}_{2} \mathrm{O}_{3}, \mathrm{Dy}_{2} \mathrm{O}_{3}$ and $\mathrm{Eu}_{2} \mathrm{O}_{3}$ were used as raw materials. Rare earth oxides $\left(\mathrm{Eu}_{2} \mathrm{O}_{3}\right.$ and $\left.\mathrm{Dy}_{2} \mathrm{O}_{3}\right)$ have the purity of $99.99 \%$ and other materials are analytical grade reagents. Calculated 
amounts of the starting materials based on the compositions of the as-designed samples were taken in an agate mortar and grounded well to obtain homogenous mixtures. The well mixed batches were put into corundum crucibles and melted in an electrical furnace at $1460^{\circ} \mathrm{C}$ for 1 hour in normal atmosphere. After melting, the glass melts were quickly casted into a preheated stainless steel mould for quenching in air. To relieve the internal stress of these glasses, which is induced during the quenching process, the obtained glass samples were annealed in a muffle furnace at $450{ }^{\circ} \mathrm{C}$ for 2 hours in normal atmosphere, followed by natural cooling.

The energy dispersive spectroscopy (EDS) was measured using an EDS detector SDD Xmax attached on the Scanning Electron Microscope (SEM, JEOL JSM 7100F) to analyze the compositions of the glasses. The excitation and emission spectra were recorded using an FLS920 fluorescence spectrometer (Edinburgh Instruments Ltd., United Kingdom). A continuous wave $450 \mathrm{~W}$ Xe lamp (Xe900) was used as a light source. The fluorescence decay curves were measured by using a standard storage digital oscilloscope and by exciting the samples at $266 \mathrm{~nm}$ with a frequency-quadrupled Nd:YAG laser providing $6 \mathrm{~ns}$ laser pulses. All the measurements were performed at room temperature and with the same measurement conditions.

\section{Results and discussion}

Since some raw materials (e.g., $\mathrm{CaF}_{2}$ and $\mathrm{ZnO}$ ) used can be volatile during the preparation of glasses, the final product composition can be different from the nominal one as designed. As mentioned before, all the investigated glasses have the same glass matrix composition. As an example, we performed the composition analysis of samples GMS4 and GMD0.5 using 
EDS technique, as shown in Fig. 1. It can be seen that the content of F, $\mathrm{Zn}$, and $\mathrm{Sb}$ reduced compared to the nominal compositions, indicating that these three elements were partially lost during preparing these glasses by melt quenching method.

Fig. 2 shows the excitation and emission spectra of Sb single doped (GMS4), Dy single doped (GMD0.5), and Sb/Dy co-doped (GMS4D0.5) glasses. The excitation spectrum of GMS4 covers a broad UV wavelength region from 230 to $355 \mathrm{~nm}$ with a maximum at about $266 \mathrm{~nm}$, corresponding to the partially forbidden ${ }^{1} S_{0} \rightarrow{ }^{3} P_{1}$ electronic transition of $\mathrm{Sb}^{3+}[\mathbf{1 6}$, 17]. Under the excitation of $266 \mathrm{~nm}$, this glass presents a broad emission band ranging from 340 to $650 \mathrm{~nm}$, which can be assigned to the electronic transition of ${ }^{3} P_{1} \rightarrow{ }^{1} S_{0}$ of $\mathrm{Sb}^{3+}[\mathbf{1 6}, \mathbf{1 7}]$. For the emission spectrum shown in Fig. 2 (b), the emissions at 480 and $574 \mathrm{~nm}$ are attributed to the ${ }^{4} F_{9 / 2} \rightarrow{ }^{6} H_{15 / 2}$ and ${ }^{4} F_{9 / 2} \rightarrow{ }^{6} H_{13 / 2}$ transitions of $\mathrm{Dy}^{3+}[\mathbf{1 8 , 1 9 ]}$. Additionally, the excitation spectrum monitored at $574 \mathrm{~nm}$ mainly exhibits eight bands peaking at $~ 245,323$, $348,363,384,423,451$, and $472 \mathrm{~nm}$, which are assigned to the electronic transitions of $\mathrm{Dy}^{3+}$ ions from ground state ${ }^{6} H_{15 / 2}$ to excited states ${ }^{4} L_{19 / 2}(323 \mathrm{~nm}){ }_{,}^{6} P_{7 / 2}(348 \mathrm{~nm}){ }^{6}{ }^{6} P_{5 / 2}(363 \mathrm{~nm})$, ${ }^{4} I_{13 / 2}(384 \mathrm{~nm}),{ }^{4} G_{11 / 2}(423 \mathrm{~nm}),{ }^{4} I_{15 / 2}(451 \mathrm{~nm})$, and ${ }^{4} F_{9 / 2}(472 \mathrm{~nm})$ [20], respectively. Additionally, the weak broad excitation band centered at $\sim 245 \mathrm{~nm}$ is due to the charge transfer band of $\mathrm{O}^{2-} \rightarrow \mathrm{Dy}^{3+}$. Fig. 2 (c) displays the emission and excitation spectra of $\mathrm{Sb} / \mathrm{Dy}$ co-doped glass GMS4D0.5, where the emission bands corresponding to the electronic transitions of $\mathrm{Sb}^{3+}$ and $\mathrm{Dy}^{3+}$ ions are observed in the emission spectrum excited at $266 \mathrm{~nm}$. It is noted from Fig. 2(c) that there is a strong overlap between the emission of $\mathrm{Sb}^{3+}$ and the excitation of $\mathrm{Dy}^{3+}$ in the range of 340 to $460 \mathrm{~nm}$. Consequently, it is expected that the energy transfer (ET) process can efficiently occur from $\mathrm{Sb}^{3+}$ to $\mathrm{Dy}^{3+}$. Furthermore, by carefully 
comparing Figs. 2(b) and 2(c), it is observed that the excitation band located at $\sim 260 \mathrm{~nm}$ in the excitation spectrum of sample GMS4D0.5 is greatly enhanced compared to the excitation spectrum of Dy single doped glass GMD0.5, which also confirms the existence of an energy transfer process from $\mathrm{Sb}^{3+}$ to $\mathrm{Dy}^{3+}$ in $\mathrm{Sb} / \mathrm{Dy}$ co-doped glass GMS4D0.5.

To further evaluate the energy transfer from $\mathrm{Sb}^{3+}$ to $\mathrm{Dy}^{3+}$ in glass GMS4D0.5, the decay curves of emission of $\mathrm{Sb}^{3+}$ were measured with excitation at $266 \mathrm{~nm}$ and monitoring at 408 nm for samples GMS4 and GMS4D0.5, as shown in Fig. 3. The decay processes of these two samples are characterized by average lifetime $\bar{\tau}$, which can be derived from: $\bar{\tau}=\int_{0}^{\infty} t I(t) d t / \int_{0}^{\infty} I(t) d t$, where $I(t)$ stands for the intensity at time $t$ [21]. The calculated lifetimes $\bar{\tau}$ are 5.77 and $5.03 \mu$ s for samples GMS4 and GMS4D0.5, respectively. The decrease of the lifetime of GMS4D0.5 with respect to GMS4 can be attributed to the ET process from $\mathrm{Sb}^{3+}$ to neighboring $\mathrm{Dy}^{3+}$. The above analysis of luminescence spectra and decay times demonstrates the presence of the ET process from $\mathrm{Sb}^{3+}$ to $\mathrm{Dy}^{3+}$ in glass GMS4D0.5.

In the present work, we find an interesting emission behavior of $\mathrm{Sb}^{3+}$ doped glass. Fig. 4 shows the emission spectra of GMS4 under different excitation wavelengths, in which a significant red-shift as well as reducing emission intensity are observed with increasing excitation wavelengths. It is known that the $\mathrm{Sb}^{3+}$ ion possesses an electron in the outermost shell in both the ground state and the excited state, thus the emission of $\mathrm{Sb}^{3+}$ is highly affected by the coordinated surroundings [16], i.e., the emission of $\mathrm{Sb}^{3+}$ ions is greatly dependent on the local structures around them. It is reported that the variation of emission peak positions sometimes suggests luminescent ions are located at multi-site positions [22]. Considering the chemical composition of sample GMS4, this glass may contain $\left[\mathrm{SiO}_{4}\right],\left[\mathrm{AlO}_{4}\right],\left[\mathrm{AlO}_{6}\right],\left[\mathrm{ZnO}_{4}\right]$ 
and $\left[\mathrm{ZnO}_{6}\right]$ structural units, which can provide various local environments and enable multiple activator sites for $\mathrm{Sb}^{3+}$ ions. In other words, in glass GMS4, emission centers $\left(\mathrm{Sb}^{3+}\right)$ are present in several different ligand fields with respective crystal field strength. Generally, the lower the surrounding crystal field strength the shorter the emission wavelength [23]. The glass GMS4 possesses various surroundings for emission centers, thus creating a distribution of energetically different emission centers that allows their excitation selection. To the best of our knowledge, no investigation has been carried out on the excitation wavelength dependent emission behavior of $\mathrm{Sb}^{3+}$ in oxyfluoride aluminosilicate glass. For the purpose of understanding the origin of this phenomenon, further studies, both theoretical and experimental, need to be performed to obtain insight into this aspect and are now underway.

The emission spectra of $\mathrm{Sb} / \mathrm{Dy} / \mathrm{Eu}$ co-doped glass GMS4D0.5E0.3 excited at various wavelengths are displayed in Fig. 5, where the emission bands correspond to the electronic transitions of $\mathrm{Sb}^{3+}, \mathrm{Dy}^{3+}$, and $\mathrm{Eu}^{3+}$ ions. All the spectra are normalized to the peak intensity of ${ }^{4} F_{9 / 2} \rightarrow{ }^{6} H_{13 / 2}$ transition of $\mathrm{Dy}^{3+}$ around $574 \mathrm{~nm}$ for comparison. The emission bands centered at $\sim 612$ and $701 \mathrm{~nm}$ arise from the ${ }^{5} D_{0} \rightarrow{ }^{7} F_{\mathrm{J}}\left(\mathrm{J}=2\right.$ and 4) electronic transitions of $\mathrm{Eu}^{3+}[\mathbf{2 4}$, 25]. As mentioned above, the emission peaking at about $410 \mathrm{~nm}$ comes from $\mathrm{Sb}^{3+}$, and the 574 and $480 \mathrm{~nm}$ emission bands correspond to $\mathrm{Dy}^{3+}$. The emission at $\sim 660 \mathrm{~nm}$ originates from the co-contribution of $\mathrm{Eu}^{3+}$ and $\mathrm{Dy}^{3+}$ considering the overlapped emissions corresponding to the ${ }^{5} D_{0} \rightarrow{ }^{7} F_{3}$ transition of $\mathrm{Eu}^{3+}$ and the ${ }^{4} F_{9 / 2} \rightarrow{ }^{6} H_{11 / 2}$ transition of $\mathrm{Dy}^{3+}$. The emission at around $754 \mathrm{~nm}$ is assigned to the ${ }^{4} F_{9 / 2} \rightarrow{ }^{6} H_{9 / 2}$ electronic transition of $\mathrm{Dy}^{3+}$. It can be seen from Fig. 5 that the violet-blue, yellow and red emission bands are exhibited in the emission spectra of $\mathrm{Sb} / \mathrm{Dy} / \mathrm{Eu}$ co-doped glass, which demonstrates the possibility of 
generating white light via the combination of these emission bands. The respective intensity of various emission bands is clearly dependent on the excitation wavelengths. This result clearly demonstrates the correlation between the chromaticity parameters of glasses and excitation wavelengths. The difference of excitation spectra corresponding to $\mathrm{Sb}^{3+}, \mathrm{Dy}^{3+}$ and $\mathrm{Eu}^{3+}$ ions (see Fig. 6) is responsible for the variation of luminescence behavior of sample GMS4D0.5E0.3 upon various excitation conditions.

Fig. 6 presents the excitation spectra of sample GMS4D0.5E0.3 monitored at four emission peak wavelengths. For the excitation spectrum monitored at $\lambda_{\mathrm{em}}=612 \mathrm{~nm}\left({ }^{5} D_{0} \rightarrow\right.$ ${ }^{7} F_{2}$ transition of $\left.\mathrm{Eu}^{3+}\right)$, several excitation bands peaking at $\sim 361,381,393,413,463$ and 530 $\mathrm{nm}$ are observed, which correspond to the electronic transitions of $\mathrm{Eu}^{3+}$ ions from ground state ${ }^{7} F_{0}$ to excited states ${ }^{5} G_{4}(361 \mathrm{~nm}),{ }^{5} G_{2}(381 \mathrm{~nm}),{ }^{5} L_{6}(393 \mathrm{~nm}),{ }^{5} D_{3}(413 \mathrm{~nm}),{ }^{5} D_{2}(463 \mathrm{~nm})$, and ${ }^{5} D_{1}(530 \mathrm{~nm})$, respectively $[\mathbf{2 6 , 2 7 ]}$. In addition, the broad excitation band with the maximum at $\sim 265 \mathrm{~nm}$ can be assigned to the charge-transfer band of $\mathrm{O} \rightarrow \mathrm{Eu}$, corresponding to the electron transfer from oxygen $2 \mathrm{p}$ orbital to the empty orbital of $\mathrm{Eu}^{3+}$ ion [25]. The spectrum monitored at $417 \mathrm{~nm}$ is due to the ${ }^{1} S_{0} \rightarrow{ }^{3} P_{1}$ transition of $\mathrm{Sb}^{3+}$. The spectra monitored at 480 and $574 \mathrm{~nm}$ are nearly the same, and are attributed to the electronic transitions of $\mathrm{Dy}^{3+}$, which are discussed previously. It is seen from Fig. 6 that the positions of the excitation bands monitored at respective emission peak wavelengths are different, leading to the variation of emission spectra for sample GMS4D0.5E0.3 under various excitation wavelengths. Efficient excitation of the $\mathrm{Sb} / \mathrm{Dy} / \mathrm{Eu}$ co-doped glasses with UV radiation is confirmed here.

The emission spectra of samples GMS4D0.5, GMS4D0.5E0.3 and GMS4D0.5E0.5 
excited at $310 \mathrm{~nm}$ are shown in Fig. 7. The dependence of emission spectra on the type and concentrations of doped activators is clearly observed. It is known that the emission color of luminescent glasses is determined by the spectral energy distribution of the emitted light. In order to look into the trace of color variation further, the Commission International de L'Eclairage (CIE) color coordinates are calculated from the emission spectra, as illustrated in Fig. 8 and Table 1. We can see that color coordinates are dependent on the glass compositions and excitation wavelengths. In particular, some color coordinates are located within the white light region of CIE diagram.

Furthermore, the correlated color temperatures (CCTs) of the luminescence glasses are also investigated. Here, we use the McCamy equation to calculate CCT from CIE color coordinates $x, y[\mathbf{2 8}]$. The CCTs of the luminescence glasses are determined by CCT $=a n^{3}+$ $b n^{2}+c n+d[28]$, where the parameters are set to $a=-449, b=3525, c=-6823.3, d=5520.33$, and $n=(x-0.3320) /(y-0.1858)$. The CCTs for different glass compositions (different types and concentrations of doped activators) as well as excitation wavelengths are listed in Table 1. These results reveal that the CCTs of the as-prepared glasses can be efficiently tuned from cold color to warm color by selecting appropriate glass compositions and excitation wavelengths.

It is seen from Fig. 8 and Table 1 that the color coordinates and CCTs can both be effectively tailored by changing the glass compositions and excitation wavelengths, which is interesting and significant for the LED lighting applications because easy adjustment of the light color becomes possible. For these investigated glasses, the wavelength-tunable UV-LEDs can be employed as the excitation source, which are modulated by a 
voltage-to-current control circuit system that allows independent manipulation of the current sent to UV-LEDs in order to adjust the wavelength of the emitted light. These results imply that the Sb-, Dy- and Eu-doped oxyfluoride silicate glasses are promising candidates for developing lighting devices with UV-LEDs as excitation source. Therefore, a smart lighting system based on the Sb-, Dy- and Eu-doped glasses is a potential future illumination source offering controllability of color hue to match specific environments and requirements.

\section{Conclusions}

In summary, Sb-, Dy-, and Eu- doped oxyfluoride silicate luminescence glasses were synthesized by melt quenching method. By varying glass compositions and excitation wavelengths, we have managed to tune the emission colors as well as CCTs of the luminescent glasses under the UV light excitation, including enabling the glasses to emit white light. This gives the flexibility to obtain smart lighting to meet special requirements. In addition, the emission behavior of $\mathrm{Sb}^{3+}$ doped glass has been studied as a function of the excitation wavelengths. We find that emission red-shift occurs with increasing excitation wavelengths, which is due to a distribution of the emission centers $\left(\mathrm{Sb}^{3+}\right)$ at various sites in the glass structure. The energy transfer from $\mathrm{Sb}^{3+}$ to $\mathrm{Dy}^{3+}$ ions occurs in $\mathrm{Sb} / \mathrm{Dy}$ co-doped glass due to the existence of a spectral overlap between the emission of $\mathrm{Sb}^{3+}$ and the excitation spectrum of $\mathrm{Dy}^{3+}$. Our study shows that the as-prepared luminescent glasses may provide a new platform to design and fabricate novel luminescent materials for LEDs lighting in the future.

\section{Acknowledgements}

We acknowledge the financial support of the Scientific Research Foundation for the 
Returned Overseas Chinese Scholars ( Grant No.20110403 ) of Jinan, China. The authors also gratefully thank Shandong Provincial Education Association for International Exchanges for providing a visiting scholar fellowship to Chaofeng Zhu to perform this work in Université de Rennes 1. We express our sincere thanks to Richard Moncorgé (Université de Caen, France) for luminescence decay curve measurements and helpful discussions.

\section{References}

[1] V.V. Atuchin, A.P. Yelisseyev, E.N. Galashov, M.S. Molokeev, Mater. Chem. Phys. 147 (2014) 1191-1194.

[2] B. Fan, B. Xue, X.H. Zhang, J.L. Adam, X.P. Fan, Opt. Lett. 38 (2013) 2280-2282.

[3] J. Zavadil, Z.G. Ivanova, P. Kostka, M. Hamzaoui, M.T. Soltani, J. Alloys Compd. 611 (2014) 111-116.

[4] W.A. Pisarski, L. Zur, T. Goryczka, M. Soltys, J. Pisarska, J. Alloys Compd. 587 (2014) 90-98.

[5] T. Mizoguchi, S.D. Findlay, A. Masuno, Y. Saito, K. Yamaguchi, H. Inoue, Y. Ikuhara, ACS Nano, 7 (2013) 5058-5063.

[6] L.J. Ren, X.H. Lei, X.Q. Du, L. Jin, W.M. Chen, Y.A. Feng, J. Lumin. 142 (2013)150-154.

[7] C.F. Zhu, J. Wang, M.M. Zhang, X.R. Ren, J.X. Shen, Y.Z. Yue, J. Am. Ceram. Soc. 97 (2014) 854-861.

[8] H. Okamoto, K. Kasuga, Y. Kubota, N. Nishimura, H. Kawamoto, K. Miyauchi, Y. Shimotsuma, K. Miura, Opt. Express 21 (2013) 22043-22052.

[9] J.W. Yang, H. Guo, Y.L. Wei, H.M. Noh, J.H. Jeong, Opt. Mater. Express 4 (2014) 315-320.

[10] L. Chen, A.Q. Luo, X.R. Deng, S.C. Xue, Y. Zhang, F.Y. Liu, J.Y. Zhu, Z.F. Yao, Y. Jiang, S.F. Chen, J. Lumin. 143 (2013) 670-673.

[11] H. Masai, S. Matsumoto, T. Fujiwara, Y. Tokuda, T. Yoko, J. Am. Ceram. Soc. 95 (2012) 862-865.

[12] G. Lakshminarayana, R. Yang, J.R. Qiu, M.G. Brik, G.A. Kumar, I.V. Kityk, J. Phys. D: Appl. Phys. 42 
(2009) 015414.

[13] L.H.C. Andrade, S.M. Lima, M.L. Baesso, A. Novatski, J.H. Rohling, Y. Guyot, G. Boulon, J. Alloys Compd. 510 (2012) 54-59.

[14] R.F. Wang, D.C. Zhou, J.B. Qiu, Y. Yang, C. Wang, J. Alloys Compd. 629 (2015) 310-314.

[15] M. Vijayakumar, K. Marimuthu, J. Alloys Compd. 629 (2015) 230-241.

[16] H.D. Zeng, Q. Yu, Z.F. Wang, L.Y. Sun, J. Ren, G.R. Chen, J.R. Qiu, J. Am. Ceram. Soc. 96 (2013) $2476-2480$.

[17] C.G. Ming, F. Song, L.Q. An, X.B. Ren, Appl. Phys. Lett. 102 (2013) 141903.

[18] L. Marciniak, D. Hreniak, W. Strek, J. Mater. Chem. C 2 (2014) 5704-5708.

[19] A.M. Kaczmarek, K.V. Hecke, R.V. Deun, Inorg. Chem. 53 (2014) 9498-9508.

[20] F. Yang, H.X. Ma, Y.F. Liu, B. Han, H. Feng, Q.M. Yu, Ceram. Int. 40 (2014) 10189-10192.

[21] H. Guo, R.F. Wei, X.Y. Liu, Opt. Lett. 37 (2012) 1670-1672.

[22] L. Irimpan, B. Krishnan, A. Deepthy, V.P.N. Nampoori, P. Radhakrishnan, J. Phys. D:Appl. Phys. 40 (2007) 5670-5674.

[23] N. Da, M.Y. Peng, S. Krolikowski, L. Wondraczek, Opt. Express 18 (2010) 2549-2557.

[24] J.C. Chen, Q.G. Meng, P.S. May, M.T. Berry, C. Lin, J. Phys. Chem. C 117 (2013) 5953-5962.

[25] S.N. Rasool, L.R. Moorthy, C.K. Jayasankar, Mater. Express 3 (2013) 231-240.

[26] B.J. Chen, E.Y.B. Pun, H. Lin, J. Alloys Compd. 479 (2009) 352-356.

[27] L.Q. Liu, E. Ma, R.F. Li, G.K. Liu, X.Y. Chen, Nanotechnology, 18 (2007) 015403.

[28] L.F. Shen, X. Liu, B.J. Chen, E.Y.B. Pun, H. Lin, J. Phys. D:Appl. Phys. 45 (2012) 115301. 


\section{Table Caption}

Table 1 Color coordinates and correlated color temperatures (CCTs) of glass samples.

Table 1

\begin{tabular}{|c|c|c|c|c|}
\hline \multirow{2}{*}{ Sample No. } & \multirow{2}{*}{$\lambda \operatorname{ex}(\mathrm{nm})$} & \multicolumn{2}{|c|}{ Color coordinate } & \multirow{2}{*}{$\operatorname{CCT}(\mathrm{K})$} \\
\hline & & $\mathrm{x}$ & $\mathrm{y}$ & \\
\hline \multirow{6}{*}{ GMS4D0.5E0.3 } & 272 & 0.39 & 0.34 & 3429 \\
\hline & 300 & 0.36 & 0.31 & 4156 \\
\hline & 310 & 0.32 & 0.29 & 6354 \\
\hline & 320 & 0.42 & 0.36 & 2915 \\
\hline & 348 & 0.41 & 0.43 & 3686 \\
\hline & 385 & 0.45 & 0.42 & 2920 \\
\hline GMS4D0.5E0.5 & 310 & 0.37 & 0.30 & 3624 \\
\hline GMS4D0.5 & 310 & 0.27 & 0.27 & 12635 \\
\hline
\end{tabular}




\section{Figure Captions}

Fig. 1. EDS spectra of samples GMD0.5 (a) and GMS4 (b). The nominal and EDS measured element content is indicated in the figure.

Fig. 2. Excitation (dashed line) and emission (solid line) spectra of glasses GMS4 (a), GMD0.5 (b), and GMS4D0.5 (c). All the spectra are normalized at respective maximum peak intensity for comparison.

Fig. 3. Luminescence decay curves of samples GMS4 and GMS4D0.5, which were obtained using the excitation wavelength of $266 \mathrm{~nm}$ and monitoring the emission at $408 \mathrm{~nm}$.

Fig. 4. Dependence of the emission spectra for sample GMS4 on the excitation wavelengths. The excitation wavelengths are explicitly indicated in the figure.

Fig. 5. Emission spectra of glass GMS4D0.5E0.3 as a function of excitation wavelengths. All the spectra are normalized at $574 \mathrm{~nm}$ peak intensity for comparison and the respective excitation wavelengths $(\lambda \mathrm{ex})$ are indicated in the figure.

Fig. 6. Excitation spectra of sample GMS4D0.5E0.3 monitored at various wavelengths. All the spectra are normalized at respective maximum excitation peak intensity and the monitored wavelengths $(\lambda \mathrm{em})$ are denoted in the figure.

Fig. 7. Emission spectra excited at $310 \mathrm{~nm}$ for samples GMS4D0.5, GMS4D0.5E0.3, and GMS4D0.5E0.5. All the spectra are normalized to the $574 \mathrm{~nm}$ peak intensity for comparison.

Fig. 8. CIE chromaticity diagrams showing the emission color variation of glasses. Points 1 to 6 (solid circle) correspond to sample GMS4D0.5E0.3 under the excitation of 272, 300, 310, 320, 348, and $385 \mathrm{~nm}$, respectively. Points 7 (solid circle) and 8 (hollow circle) 
are assigned to samples GMS4D0.5 and GMS4D0.5E0.5 excited at $310 \mathrm{~nm}$.
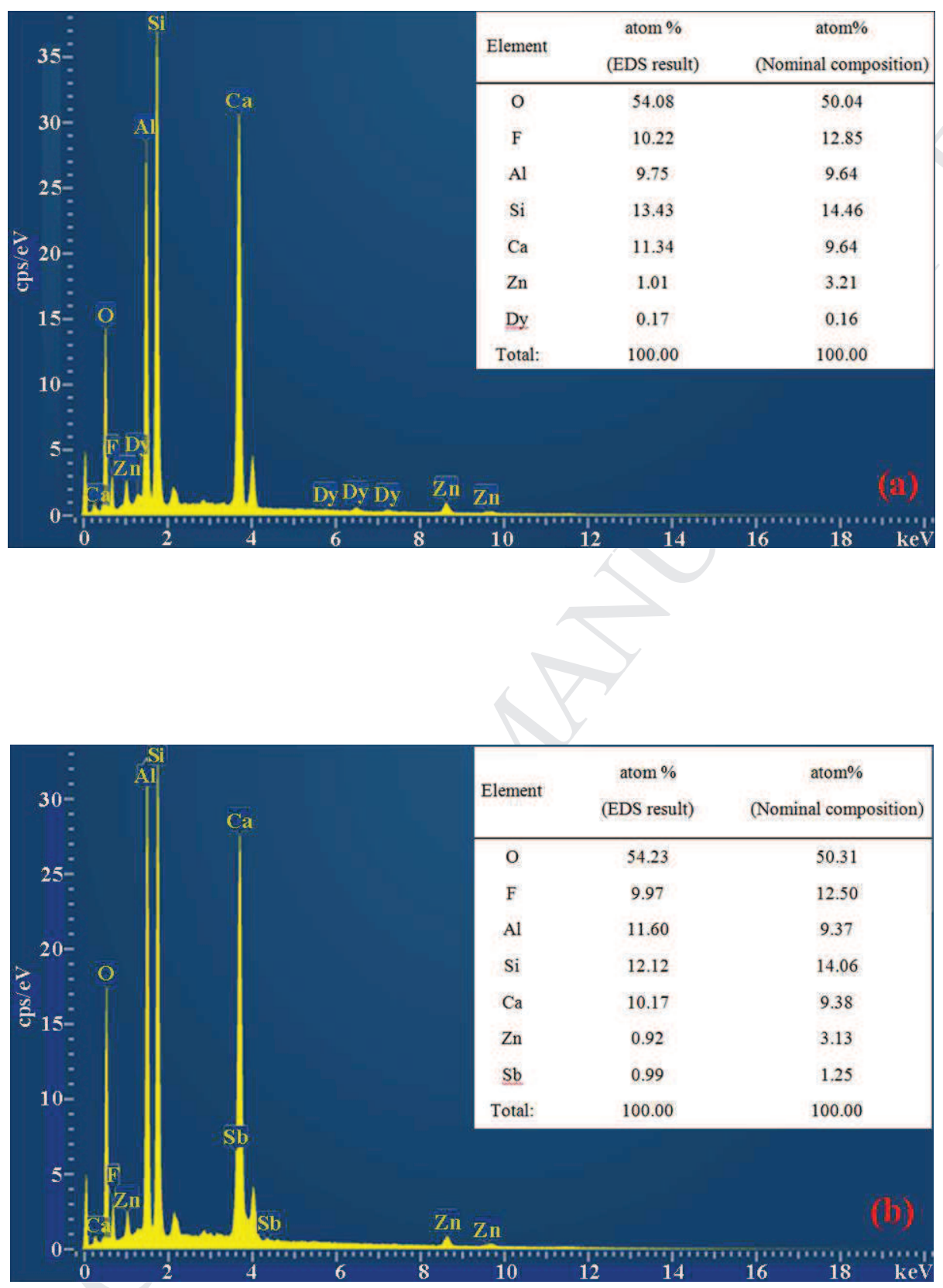

Fig. 1. EDS spectra of samples GMD0.5 (a) and GMS4 (b). The nominal and EDS measured element content is indicated in the figure. 

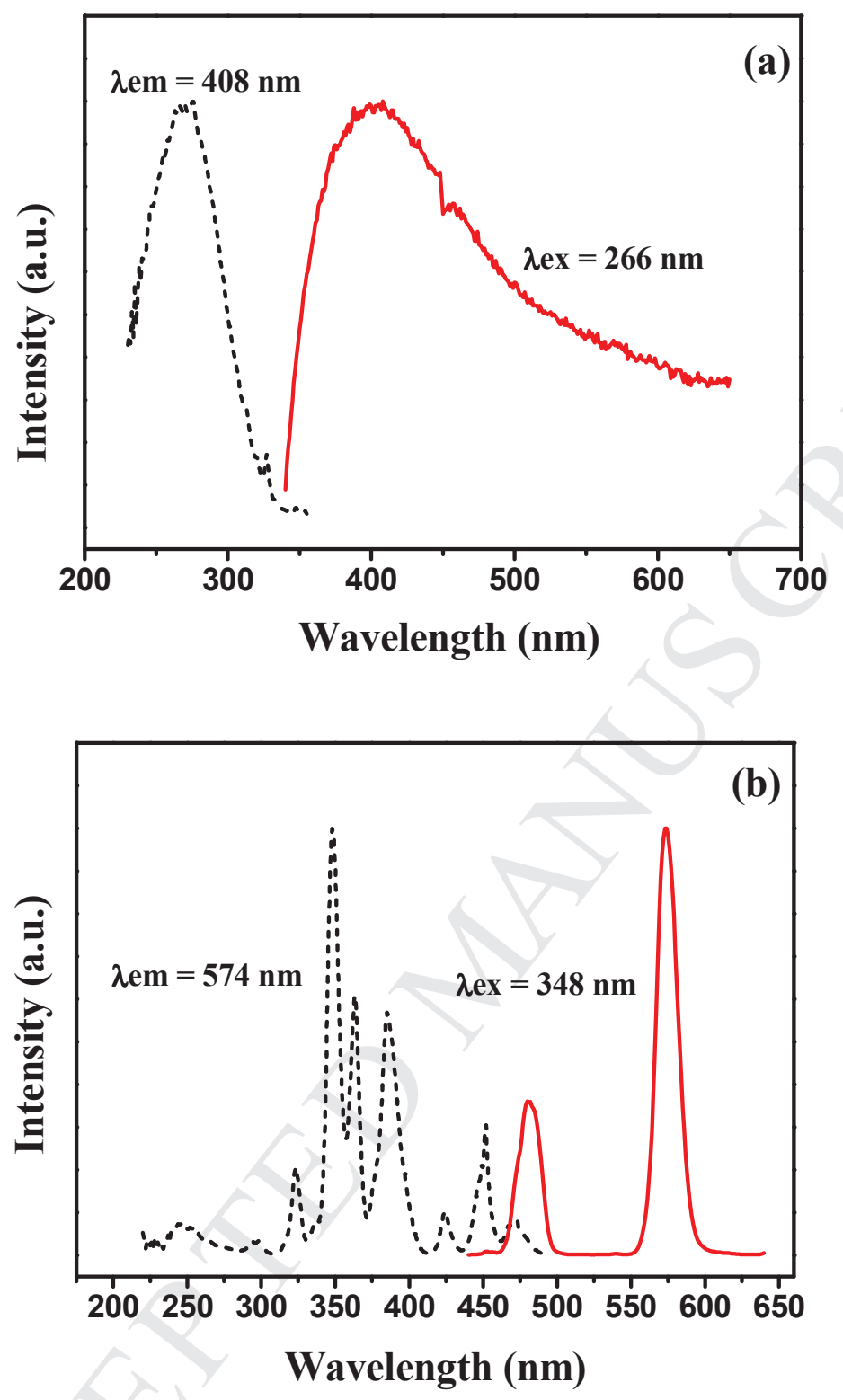


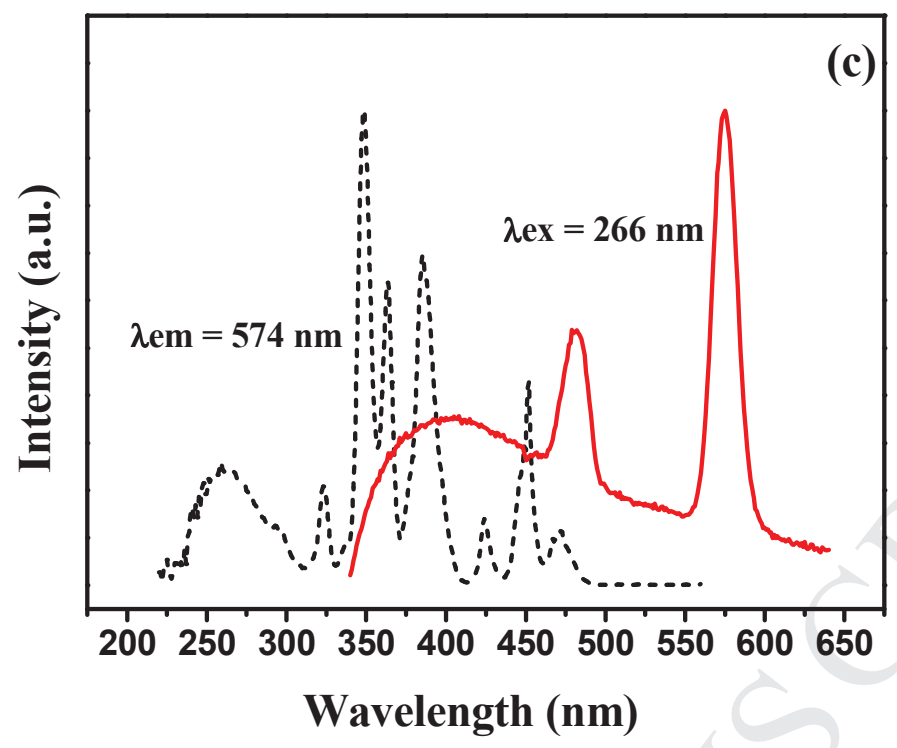

Fig. 2. Excitation (dashed line) and emission (solid line) spectra of glasses GMS4 (a), GMD0.5 (b), and GMS4D0.5 (c). All the spectra are normalized at respective maximum peak intensity for comparison.

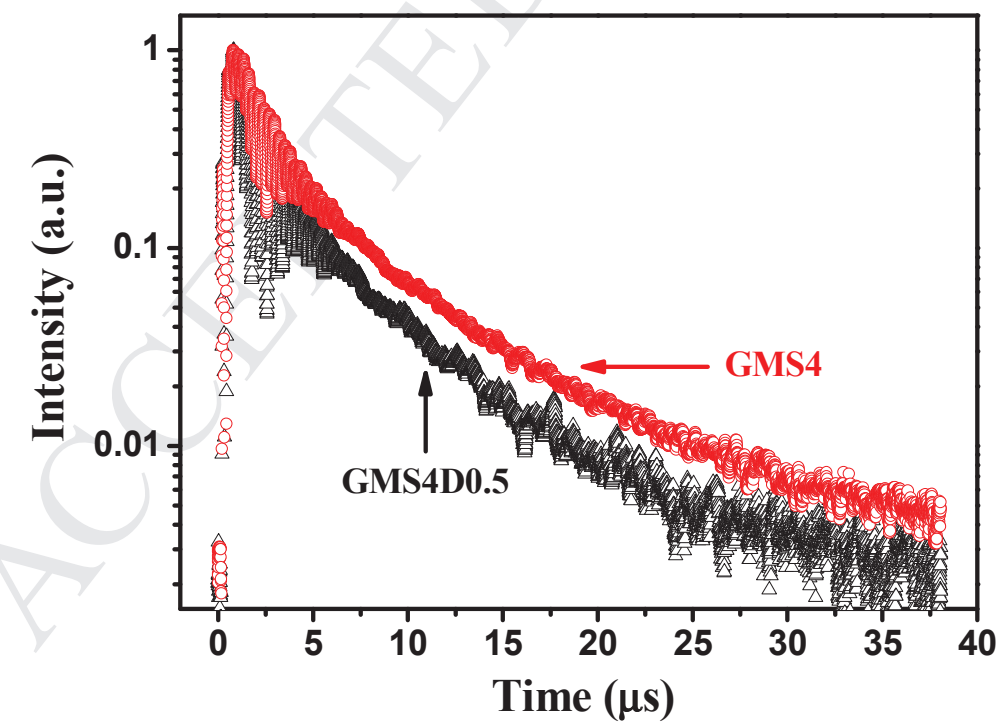

Fig. 3. Luminescence decay curves of samples GMS4 and GMS4D0.5, which were obtained using the excitation wavelength of $266 \mathrm{~nm}$ and monitoring the emission at $408 \mathrm{~nm}$. 


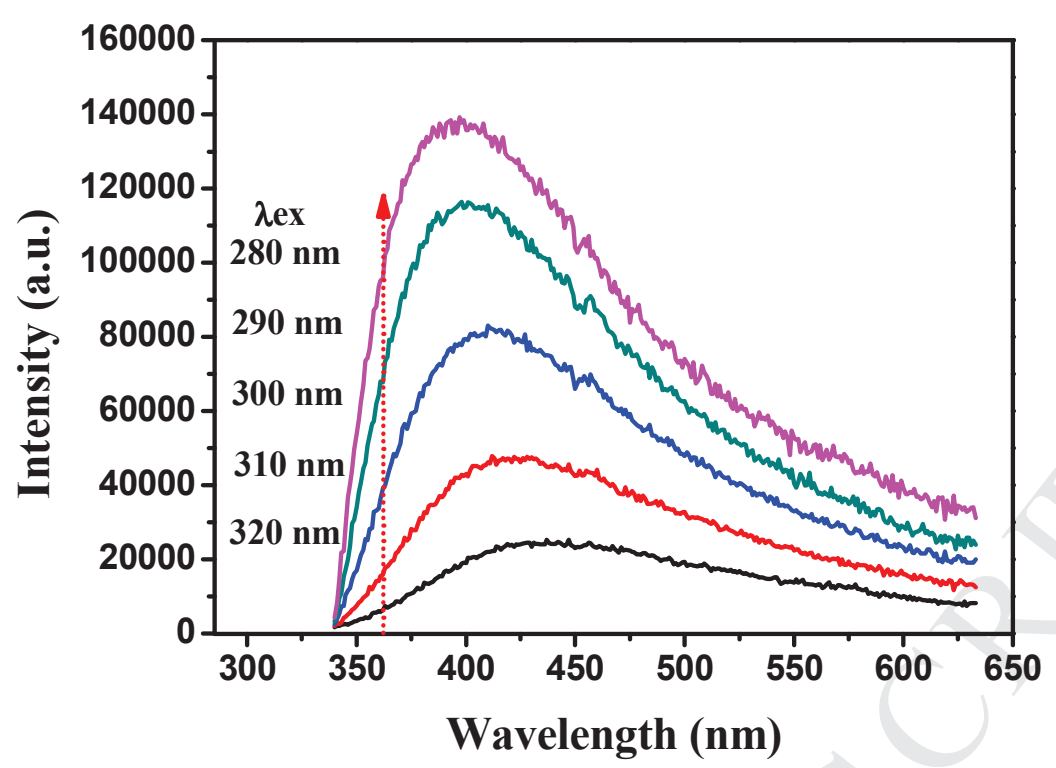

Fig. 4. Dependence of the emission spectra for sample GMS4 on the excitation wavelengths.

The excitation wavelengths are explicitly indicated in the figure.

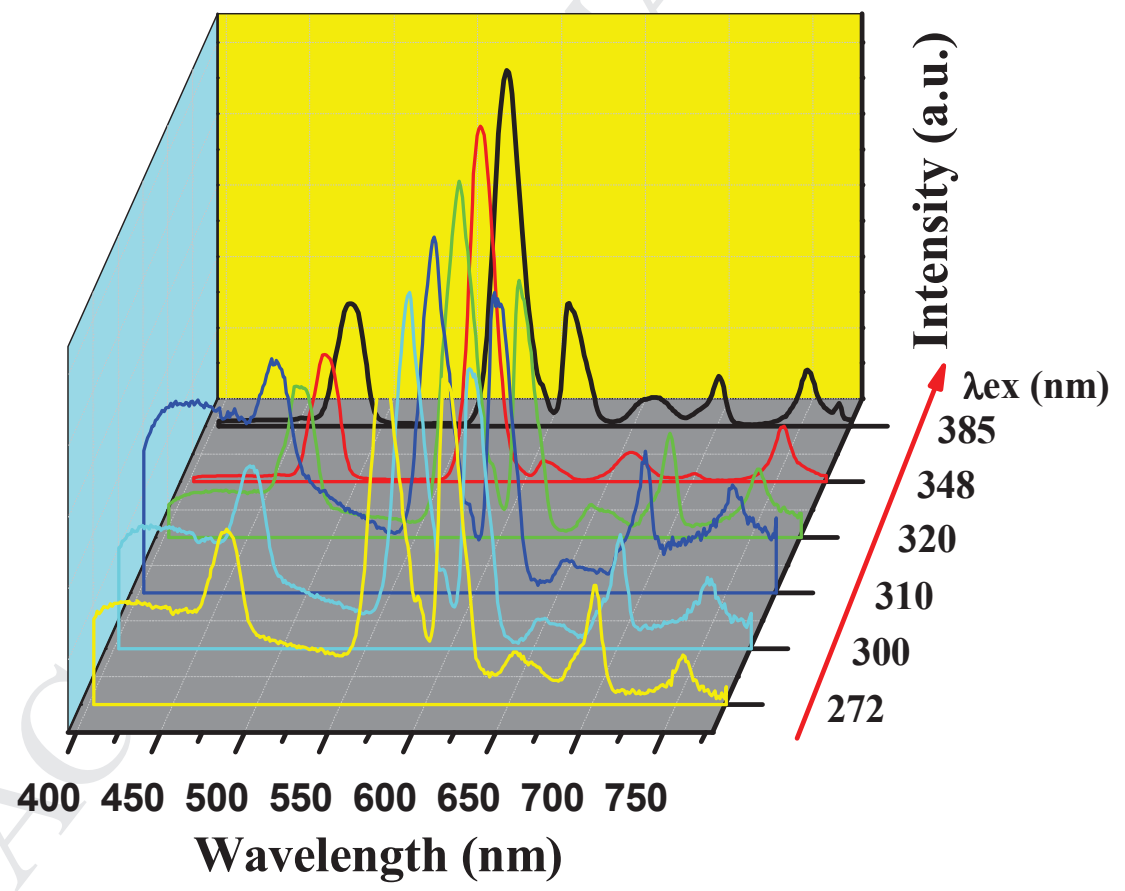

Fig. 5. Emission spectra of glass GMS4D0.5E0.3 as a function of excitation wavelengths. All the spectra are normalized at $574 \mathrm{~nm}$ peak intensity for comparison and the respective excitation wavelengths ( $\lambda$ ex) are indicated in the figure. 


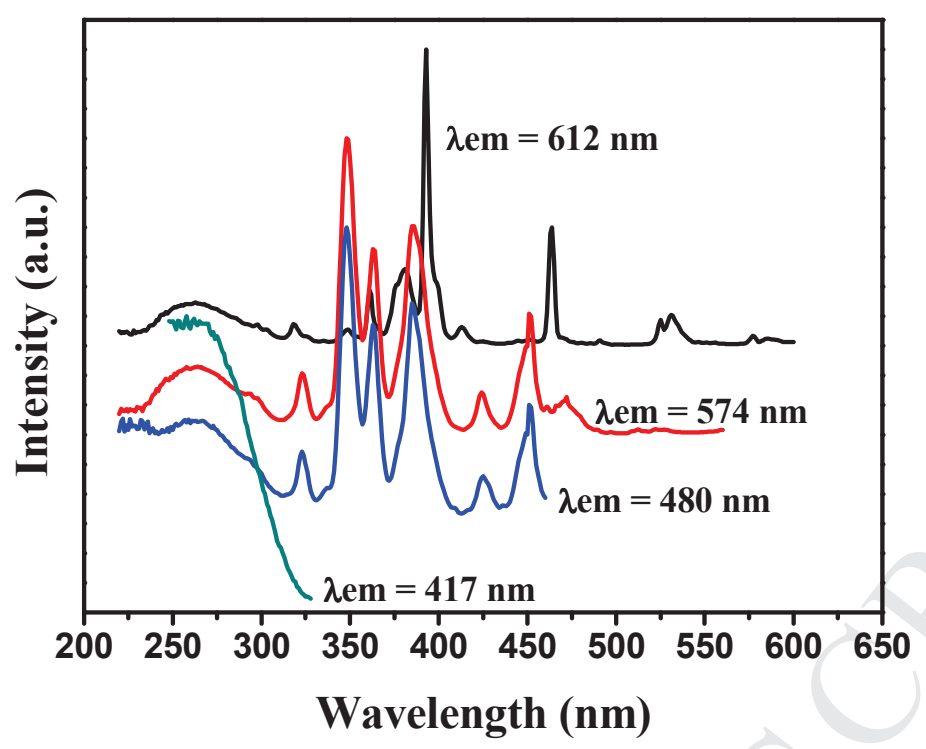

Fig. 6. Excitation spectra of sample GMS4D0.5E0.3 monitored at various wavelengths. All the spectra are normalized at respective maximum excitation peak intensity and the monitored wavelengths $(\lambda \mathrm{em})$ are denoted in the figure.

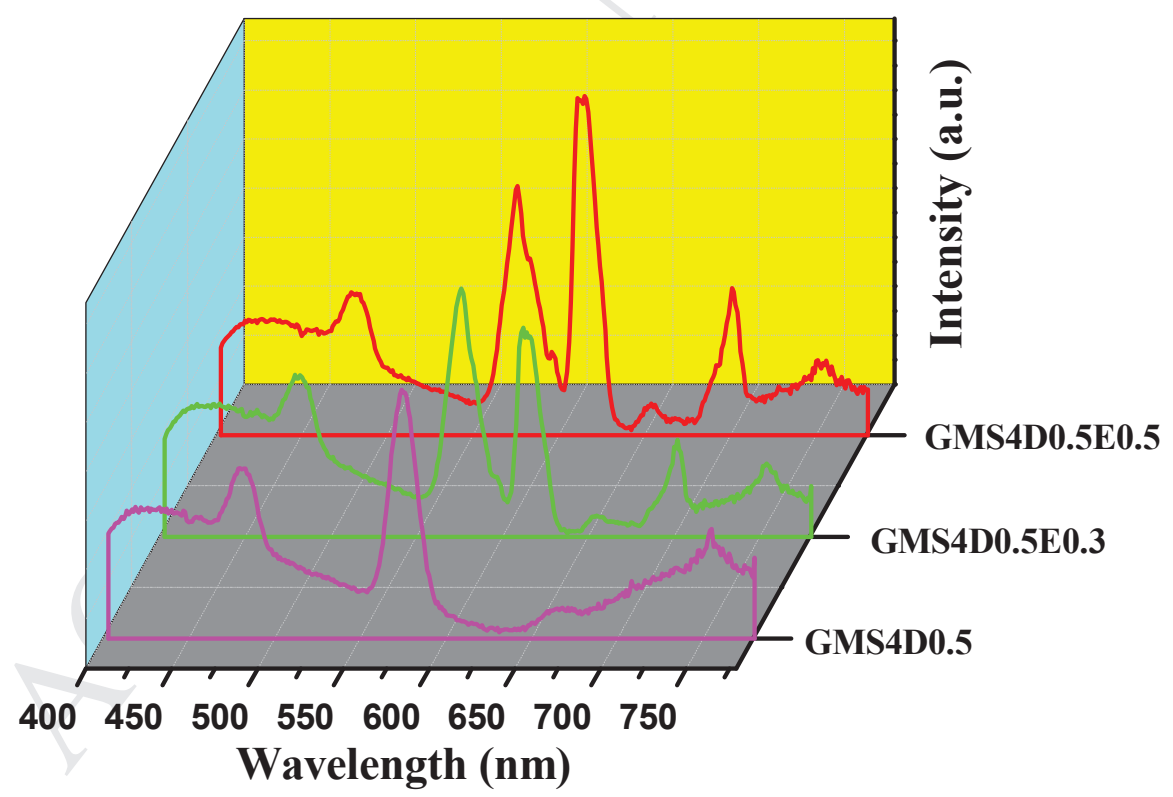

Fig. 7. Emission spectra excited at $310 \mathrm{~nm}$ for samples GMS4D0.5, GMS4D0.5E0.3, and GMS4D0.5E0.5. All the spectra are normalized to the $574 \mathrm{~nm}$ peak intensity for comparison. 


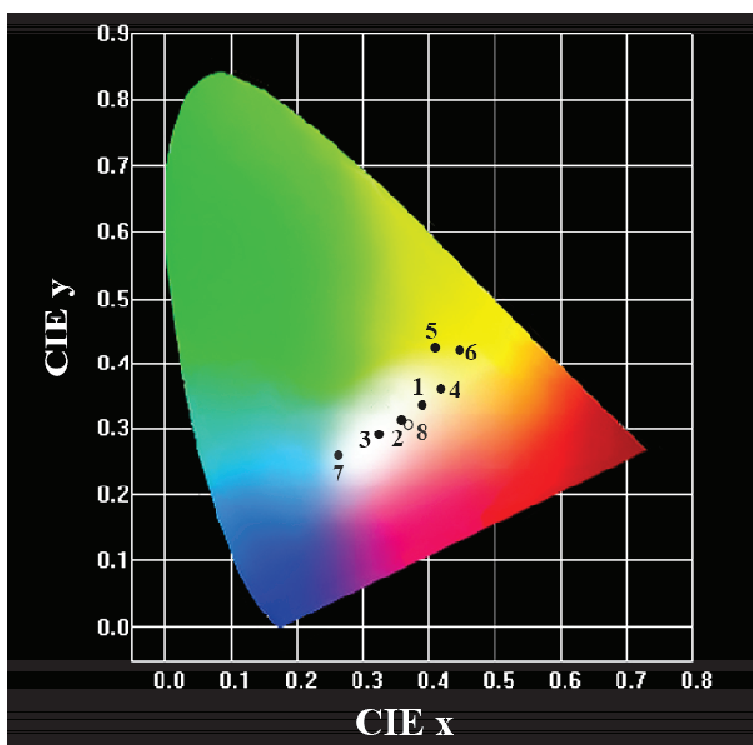

Fig. 8. CIE chromaticity diagrams showing the emission color variation of glasses. Points 1 to 6 (solid circle) correspond to sample GMS4D0.5E0.3 under the excitation of 272, 300, 310, 320, 348, and $385 \mathrm{~nm}$, respectively. Points 7 (solid circle) and 8 (hollow circle) are assigned to samples GMS4D0.5 and GMS4D0.5E0.5 excited at $310 \mathrm{~nm}$. 


\section{Highlights}

- Sb-, Dy-, and Eu-doped oxyfluoride glasses for LED applications are studied.

- Emission red-shift occurs with increasing excitation wavelength for Sb-doped glass.

- Energy transfer from $\mathrm{Sb}^{3+}$ to $\mathrm{Dy}^{3+}$ ions occurs in $\mathrm{Sb} / \mathrm{Dy}$ co-doped glass.

- White light emission is achieved for $\mathrm{Sb} / \mathrm{Dy} / \mathrm{Eu}$ co-doped glasses. 